\title{
Histórias de Dor e de Vida: oficinas de contadores de histórias
}

\section{Stories of Life and Pain: storytellers workshops}

Stela Nazareth Meneghel

Médica Sanitarista, Professora e Pesquisadora do Programa de Pós Graduação em Saúde Coletiva/UNISINOS.

Endereço: Rua Santo Antonio, 6II apto 32, CEP 90220-oII, Porto Alegre, RS, Brasil.

E-mail: smeneghelळhotmail.com

\section{Olga Farina}

Filósofa e fundadora da ONG Apoio, Solidariedade e Prevenção à Aids/São Leopoldo.

Endereço: Rua São Caetano, 965, CEP 93010-090, São Leopoldo, RS, Brasil.

E-mail: aspaळaspa.org.br

\section{Luciano Bairros da Silva}

Acadêmico de psicologia da UNISINOS, Bolsista Iniciação Científica. Endereço: Av Unisinos, 950, CEP 93220-000, São Leopoldo, RS, Brasil.

E-mail: lucianopsico®yahoo.com.br

\section{Leandro Walter}

Acadêmico de psicologia da UNISINOS, Bolsista Iniciação Científica. Endereço: Av Unisinos, 950, CEP 93220-000, São Leopoldo, RS, Brasil. E-mail: nandowalterळpop.com.br

\section{Sarita Gisele Brito}

Acadêmico de psicologia da UNISINOS, Bolsista Iniciação Científica. Endereço: Av Unisinos, 950, CEP 93220-000, São Leopoldo, RS, Brasil.

E-mail: cybergisaळhotmail.com

\section{Lucilda Selli}

Professora e pesquisadora do Programa de Pós Graduação em Saúde Coletiva/UNISINOS.

Endereço: Av. Unisinos, 950 CEP 93220-000 São Leopoldo, RS, Brasil E-mail: lucildaselli®terra.com.br

\section{Vânia Schneider}

Mestre em Saúde Coletiva/UNISINOS.

Endereço: Av. Unisinos, 950 CEP 93220-000 São Leopoldo, RS, Brasil

E-mail: vaniaœnis.com.br

\section{Resumo}

Esta pesquisa foi uma intervenção com grupos de sujeitos soropositivos, realizada na cidade de São Leopoldo/RS, município da região metropolitana de Porto Alegre que apresenta a terceira prevalência de Hiv/ Aids no Estado. 0 objetivo da pesquisa foi organizar oficinas de contadores de histórias e motivar os participantes a atuar como multiplicadores. A oficina de que trata este artigo foi realizada na ONG Apoio, Solidariedade e Prevenção à Aids (ASPA), desenvolvida em cinco encontros, nos quais os sujeitos contaram as histórias de vida e inventaram um ritual ancorado na religiosidade popular. 0 grupo era composto por oito usuários e dois trabalhadores voluntários, todos soropositivos; com predomínio de mulheres de baixa renda e chefes de família. Foi utilizado o referencial das práticas discursivas para analisar o material produzido na oficina. No percurso do trabalho emergiram dois temas principais: o preconceito a que estão submetidos os sujeitos soropositivos e a religiosidade como estratégia de resistência usada pela população na luta contra a Aids. Enfatiza-se a importância de atividades como a de contar histórias na promoção da saúde da população.

Palavras-chave: Educação em saúde; Narrativas; HIV/ Aids. 


\section{Abstract}

The present research is a result of an intervention with HIV-positive individuals carried out in the city of São Leopoldo (Brazil, state of Rio Grande do Sul), a municipality located in the Porto Alegre metropolitan area with the third highest number of HIV/Aids cases in the region. The aim of the research was to organize workshops for storytellers and motivate the participants to spread the word. The workshop described in this article took place at the NGO Apoio, Solidariedade e Prevenção à Aids (ASPA - Aids Prevention, Solidarity and Support), and was developed throughout five meetings when the participants told life stories and created a ritual based on popular religiosity. The group was composed of eight users and two volunteer workers, all of them HIV-positive; the majority were female, with a low income, living in areas of difficult access and heading their households. As for the theoretical framework, we used discourse practices in order to analyze the material produced in the workshops. Throughout the activity, two main themes emerged: the prejudice imposed upon HIV-positive individuals and religiosity as a strategy for confronting Aids. Emphasis is given to the importance of storytellers workshops in the promotion of the health of the population.

Keywords: Health Education; Narratives; HIV/Aids.

\section{Introdução}

Este estudo faz parte de uma pesquisa denominada "Histórias de resistência de mulheres", desenvolvida na Universidade do Vale do Rio dos Sinos (UNISINOS) e realizada no município de São Leopoldo/Rio Grande do Sul. São Leopoldo é uma das cidades que compõe a região metropolitana de Porto Alegre, onde se encontram 70\% dos casos de Aids do Rio Grande do Sul. O município apresenta índices elevados de violência (Hennington e Meneghel, 2005) e a terceira prevalência de HIV/Aids na região (ASPA, 2005).

No Brasil, a incidência da Aids está aumentando em mulheres, ao mesmo tempo em que a queda da mortalidade é menor nesse grupo. A tendência atual da epidemia é heterossexualização, feminização, interiorização e pauperização (Brasil, 2005). A desigualdade de gênero é considerada um dos suportes sociais para a feminização da doença, dificultando a negociação do sexo seguro e expondo as mulheres a fazer sexo com coortes de homens mais velhos, onde as prevalências de DSTs/Aids são maiores (Bastos e Szwarcwald, 200o), indicando o quanto as vulnerabilidades do gênero feminino não podem ser abstraídas daquelas decorrentes da pobreza (Giffin, 2002).

Essa pesquisa constituiu uma intervenção na qual foi explorada a ferramenta de contar histórias em oficinas com sujeitos soropositivos, a partir da constatação de que as narrativas podem ajudar a mudar a vida das pessoas, através da reconstrução das histórias de vida, tanto dos contadores, quanto dos ouvintes (Benjamin, 1980; Carvalho, 2003; Caprara e Veras, 2005; Connelly e Clandinin, 1995; Goolishian e Anderson, 1996).

Nas rodas de histórias, partimos sempre das experiências dos membros do grupo em relação às vivências, à cotidianidade e às vulnerabilidades. 0 compartilhar de narrativas entre os participantes possibilita romper segredos de longo tempo, expor fragilidades, agregar um outro olhar, um outro ponto de vista às histórias de vida. $\mathrm{O}$ fato de as histórias serem contadas no grupo permite buscar um sentido para a experiência da doença, minimizar os sentimentos de vergonha e de culpa e possibilitar o aflorar de estratégias para enfrentar a soropositividade.

Grupos para contar histórias permitem aos narradores posicionarem-se como sujeitos do discurso 
(Salotti e França, 2005), dando voz aos participantes de pesquisa, que em situações de investigação participativa estão autorizados a contar suas histórias. A investigação narrativa é um processo cooperativo no qual as pessoas vivem e contam as histórias de vida, ao mesmo tempo. Ao narrar uma história, uma mesma pessoa está ocupada em viver, em explicar, em re-explicar e reviver as histórias, em um processo em que todas as vozes podem ser ouvidas (Connelly e Clandinin, 1995).

As histórias são depoimentos de como as pessoas se apropriam dos acontecimentos de suas vidas, deste modo, todas as narrativas são consideradas verdadeiras. 0 contar histórias faz parte do processo de construção de identidade individual e coletiva, na medida em que somos construídos pelas histórias que contamos ou que nos foram contadas para e sobre nós (Goolishian e Anderson, 1996).

Ao construir oficinas de contadores de histórias embasadas nas técnicas de narrativa oral, o objetivo era enriquecer a caixa de ferramentas dos trabalhadores de saúde e usuários dos serviços com um dispositivo capaz de fortalecer as estratégias de resistência empreendidas por esses sujeitos. A arte de contar histórias pode ser usada nas práticas de saúde coletiva e educação em saúde, na medida em que as narrativas são poderosos dispositivos de remodelação das experiências passadas segundo a ótica do presente, permitindo ressignificar experiências vividas, inclusive as de aflição e de adoecimento.

\section{Trajeto Metodológico}

Esta é uma pesquisa-intervenção, uma estratégia de conhecimento em que os participantes e os pesquisadores estão envolvidos de modo cooperativo. Neste artigo, realizamos o relato das experiências vividas nessa intervenção, inspirada nos referenciais da pesquisa-participante (Brandão, 1988; Thiollent, 1980). Para Morin (2004), a pesquisa participativa é apropriada para a abordagem de objetos e fenômenos sociais complexos e em evolução. É um método que visa uma ação estratégica e envolve a participação dos atores, exigindo engajamento pessoal e relações dialógicas. Constitui uma tentativa de solução de questões específicas de grupos sociais alijados do poder e, nos dias atuais, tem sido utilizada no trabalho com as minorias: mulheres, usuários de drogas, migrantes, sujeitos em situação de vulnerabilidade. Além disso, pesquisas que utilizaram o dispositivo grupal com sujeitos soropositivos têm apresentado resultados satisfatórios (Brasil, 2003; Rasera e Japur, 2003).

Assim, nos alinhamos aos referenciais teórico-participativos para instrumentalizar a criação das oficinas de contadores de histórias. As oficinas são espaços de trabalho coletivos, onde há lugar para as atividades concretas e artísticas. Constituem dispositivos de trabalho determinados por práticas histórico-sociais utilizadas para estimular a autonomia dos participantes através da dialogicidade e da reinvenção do cotidiano (Jeolás e Ferrari, 2003; Meneghel e col., 2005; Brasil, 2003; Rauter, 2000). As oficinas vão se construindo durante a própria intervenção, já que está implícita a participação de todos os membros do grupo que intervêm ativamente durante o processo. Desta maneira, foram propostas algumas etapas provisórias, sabendo que elas seriam reformuladas durante o processo.

\section{Negociação da entrada em campo}

O locus da intervenção foi a ONG ASPA - Apoio, Solidariedade e Prevenção à Aids, que atua junto à comunidade do Vale do Rio dos Sinos e dedica-se à melhoria da qualidade de vida na região, com o enfoque na prevenção de DST's/Aids. Desde sua fundação, em 1991, vem contribuindo para a implantação, a qualificação e o controle social de políticas públicas relacionadas com a prevenção das DST's/Aids. Uma das pesquisadoras é membro fundador, trabalha na ONG e sua presença foi imprescindível para o trabalho.

\section{Realização da oficina}

O planejamento e realização da oficina foram organizados pelo grupo de pesquisa, em conjunto com representantes da ONG. O objetivo inicial era o de que as mulheres mães de crianças soropositivas contassem suas histórias de vida e, ao mesmo tempo, fossem confeccionando um "Álbum de Vida" com os eventos significativos vivenciados pela díade mãe-filho. O Álbum propiciaria espaço para as mulheres documentarem aspectos das histórias de vida e preservarem a memória da família.

A proposta inicial compreendia três encontros, que foram ampliados para cinco a pedido dos participantes, com os temas: histórias de vida dos participan- 
tes, cantigas de roda, Álbum de Vida, celebração, oferta do álbum e avaliação. 0 objetivo de incluir as cantigas de roda era o de rememorar a infância, e a oferta do álbum representaria um legado de vida, uma estratégia para enfrentar a doença. Operou-se com a arte e o ritual, como dispositivos para ajudar a entender e a ressignificar a doença (Meneghel e col., 2005).

As oficinas foram coordenadas por pesquisadores pertencentes aos campos da saúde coletiva, comunicação e psicologia. A pesquisa foi aprovada pelo CEP/ UNISINOS e todos os participantes concordaram em participar, após a leitura conjunta do TCLE e explicitação dos objetivos da pesquisa. Escolheram-se nomes bíblicos para identificar os participantes da pesquisa, em uma alusão à religiosidade que emergiu durante a oficina.

\section{Análise das oficinas}

O plano de análise desse estudo articulou-se à psicologia discursiva, na qual assume dimensão central o estudo da linguagem enquanto constituinte de práticas sociais produtoras da realidade e da construção de sentidos. A dialogicidade permeia a produção discursiva, na medida em que a comunicação acontece entre interlocutores e permite que os sujeitos sejam constituídos e reconstituídos através das práticas discursivas (Iñiguez, 2004; Spink, 2004a, 2004b).

Para fins de análise, considerou-se o corpo textual produzido em um dos encontros e transcrito pela equipe da pesquisa. 0 processo iniciou com a descrição seqüencial da oficina, a partir dos registros pormenorizados nos Diários de Campo. Os grupos não foram gravados devido ao pedido dos participantes, que não se opuseram a que se tomassem notas durante o processo. 0 escrutínio do material textual permitiu a identificação dos temas principais presentes nos diálogos dos oficineiros. A partir desses temas, foram elencados todos os termos, vocábulos e expressões que compõem o repertório usado para referenciar o assunto. Os repertórios interpretativos, um conceito introduzido por Potter e Wheterell (1987), são os modos pelos quais as pessoas comunicam os conteúdos de suas falas e incluem as palavras, as figuras de linguagem, as metáforas e outros termos específicos. Eles permitem ver como os falantes definem planos no discurso através da colocação estratégica de temas (Iñiguez, 2004).
A análise das oficinas buscou entender as maneiras pelas quais as pessoas, por meio da linguagem verbal e artística, posicionam-se nas relações sociais cotidianas e produzem sentidos para experiências como as de aflição e de doença. 0 sentido é uma produção social, um empreendimento coletivo e interativo, por meio do qual as pessoas, na dinâmica das relações sociais, constroem os termos a partir dos quais lidam com as situações e fenômenos a sua volta. Os processos de produção de sentido implicam a existência de interlocutores variados, cujas vozes se fazem presentes, discutem, argumentam e complementam-se entre si (Spink, 2004 a, 2004b).

\section{Os Efeitos da Intervenção}

A oficina aqui descrita aconteceu em uma organização não-governamental situada na região metropolitana de Porto Alegre, em cinco encontros realizados em sábados à tarde. Os participantes da oficina já se reuniam na ONG em um espaço onde conversavam sobre a doença e recebiam algum tipo de auxílio, geralmente uma cesta básica e roupas. Além da equipe da pesquisa, participaram do grupo oito pessoas portadoras do vírus e dois trabalhadores voluntários soropositivos. O grupo era constituído predominantemente por mulheres, com inserção social precária - todas de baixa renda, exceto uma das voluntárias; algumas vivendo sozinhas, por viuvez ou separação de chefes de família. A maioria das pessoas encontrava-se em situação de exclusão do processo produtivo e do usufruto de bens e serviços da sociedade e procuraram a ONG devido às ações de caráter beneficente. Os serviços de saúde e mesmo as ONGs, a despeito do discurso progressista, ainda mantêm o atendimento pautado no assistencialismo, atravessado por discriminações e estimulando relações de dependência dos usuários em relação às equipes.

Nos diálogos ocorridos nas oficinas, foram identificados dois temas principais, acompanhados dos respectivos repertórios interpretativos: o da discriminação/preconceito em relação à soropositividade e o da religiosidade popular.

O repertório do preconceito/discriminação esteve presente no grupo em diversos momentos. Ester falou de um motorista de ônibus que, ao olhar sua carteira de passagem gratuita, inquiriu: o que tu andou fazen- 
do, hein!? Na cidade onde moro, se uma pessoa emagreceu rápido, já é rotulada de aidética e eles são muito preconceituosos. Sara mencionou uma pessoa que, ao saber que ela era portadora, lhe disse: em quatro anos tu não vai mais tá aqui. Jezebel contou da morte de uma participante do grupo, ocorrida poucos dias antes e que a depressão toma conta quando uma pessoa do grupo morre, tem alguns que deixam de vir. Falar sobre os preconceitos parece ter o mesmo significado da queixa no discurso das pessoas vitimizadas, do dar-se conta das violências (estruturais, interpessoais e simbólicas) a que as pessoas estão expostas e pode significar um "basta" a esta situação.

Na investigação narrativa é importante que o investigador escute a história do participante, situação que não implica no silêncio do investigador. Isso significa que se dá tempo e espaço aos participantes, que por longo tempo ocuparam o lugar do silenciado, para que contem suas histórias e para que essas histórias ganhem a validade dos relatos oficiais (Carvalho, 2003; Connelly e Clandinin, 1995). Na oficina, os participantes contaram suas histórias de vida e a equipe da pesquisa escolheu outras para contar a eles. Uma das histórias que contamos foi um conto do folclore alemão, em que uma camponesa borda o quadro da vida, enquanto enfrenta e supera um sem-número de problemas e obstáculos. 0 objetivo era discutir a possibilidade de romper com os determinismos e vislumbrar a possibilidade de refazer a própria vida. Ao perguntar o que pensaram sobre a história, Jonas declarou que sua vida era um quadro preto e que o quadro se transformou porque ele colocou cores sobre o preto. Jezebel contou que antes de adoecer vivia na noite e deixava os filhos aos cuidados da avó e afirmou que é mais feliz hoje do que antes de saber o diagnóstico e a Aids é uma benção na minha vida.

Durante o processo vivido no grupo de contadores de histórias, o jargão biomédico com o qual fomos recepcionados foi sendo substituído por outro, composto por asserções e metáforas em torno da espiritualidade como forma de enfrentamento da Aids, em diálogos que, às vezes, nos pareciam desconexos, descontextualizados ou sem sentido. Porém, foi a partir das referências religiosas que eles alavancaram a produção de sentidos para o adoecer e para o morrer, portanto, para o viver.
Sara: Isto eu aprendi. Eu aprendi assim, depois que eu tive este problema todo, que agora não é mais problema. Depois eu aprendi. Antes eu tinha mágoa das pessoas. Hoje eu digo: meu coração é puro, não fica mais mágoa. Agora podem fazê o que quiserem e eu não fico mais com mágoa.

Pesquisadora: O que aconteceu para não ser mais problema?

Sara: Pela fé... Deus guarda a pessoa do inimigo. Quando tem uma féviva no coração, Deus começa a agir, Deus te guarda a té com a morte. Ele (uma pessoa mencionada anteriormente) disse que eu não ia tá viva. E por graça de Deus eu tô aqui. Eu tinha 30 e poucos anos, hoje eu tenho 47. Os médicos dizem que se tu tivé força de vontade, tu vive mais. Prámim éfé.

Jezebel: Porque tu aceitô Cristo e aceitô a diferença. Eu era diferente. A minha convivência com a minha família mudou. Hoje eu também conheço a palavra, isto me faz muito bem. Eu procuro ler a biblia todos os dias.

Diante da doença, a gente experimenta um pouco de tudo. Pentecostais, evangélicos, Nova Era, Fraternidade Branca foram algumas das crenças que eles mencionaram. Nos repertórios estava presente a voz de Deus, a palavra, o perdão, os anjos, a leitura da biblia, a fé, o coração aberto, Cristo, o Senhor, Deus está comigo.

Em um dado momento da oficina, uma das mulheres tirou um papel da bolsa e leu "O senhor o assistirá no seu leito de dores, e na sua doença o reconfortará”. (Sal 40,4). Perguntamos a ela o porquê de ter escolhido essa mensagem. Sara, a mulher que leu o salmo, respondeu que o retirou ao acaso do conjunto de salmos que leva na bolsa e que costuma ler a palavra de deus. Sempre a palavra fala comigo. Deus é um só.

Sara mexe na bolsa, retira mais uma mensagem e lê, outra vez, o mesmo salmo de lamentação: "O senhor o assistirá no seu leito de dores, e na sua doença o reconfortará”. A equipe da pesquisa questionou o fato de ter aparecido outra vez a mesma mensagem e Sara reafirmou que o salmo foi retirado pela segunda vez por acaso. Começou, então, de uma forma exploratória, uma construção coletiva, na qual Sara retirava e lia uma mensagem para cada membro do grupo. As pessoas se diziam reconfortadas ao ouvir o salmo que lhes era lido. 
O grupo compôs um jogo, dando voz a Sara e permitindo que ela fizesse uso do poder da palavra.

A história contada por Sara e a repercussão que ela ocasionou nos motivou a contar ao grupo a história de Esculápio, o curador ferido. A leitura que fizemos foi a de que a "doença/ferida" possibilitou a experimentação dos poderes de "ressignificação/cura". Esse poder de cura foi compartilhado no grupo e se manifestou no desejo de alguns sujeitos em trabalhar na ONG e no compromisso em ajudar a outras pessoas em situação de vulnerabilidade.

\section{0 que aprendemos nas oficinas?}

Embora o debate sobre a Aids tenha se difundido amplamente nas últimas décadas e tenha mudado o enfoque sobre a doença, ainda permanece a resposta social de rejeição por meio da manutenção da lógica de exclusão (Vermelho, 1999). O preconceito foi denunciado no grupo como uma conduta corriqueira de populares, familiares, vizinhos, colegas de trabalho e presente nos serviços de saúde. Eles nos disseram que enfrentam o preconceito através do segredo, do silêncio sobre a doença e a situação de soropositividade, mantido com o aval da equipe de saúde e dos militantes da ONG.

No grupo de contadores de histórias, as narrativas deram espaço para a ressignificação das histórias pessoais por meio do fortalecimento da identidade pessoal e coletiva, ou seja, através delas foi dado outro sentido para a doença e para a dor. Como no estudo de outros autores (Garay e col., 2005), percebemos que as narrativas podem ser eficazmente utilizadas na construção de relatos autobiográficos por pessoas que tiveram as linhas argumentativas de suas vidas rompidas por traumas de guerra, abusos sexuais ou doenças graves, e que puderam reconstituir suas vidas através de narrações.

A unidade do mundo é polifônica, afirmou Bakhtin (1981), está nas múltiplas vozes que participam do diálogo da vida. As práticas discursivas estão sempre atravessadas por vozes, mesmo quando a impressão é a de um monólogo, quando alguém conversa consigo mesmo, quer seja no passado, no presente ou no futuro. Ou quando alguém, como Sara, conversa com deus. Ao contar as histórias, os participantes seguiam suas próprias linhas argumentativas, falando ora no presente, ora no passado, ora com os membros do grupo, ora com outras personagens ausentes. Múltiplas vozes tecendo uma história e indicando que a compreensão dos sentidos é sempre um confronto entre inúmeras vozes, onde nos deparamos com a polissemia e com a contradição (Spink, 2004b).

Ao avaliar as oficinas, questionamos se realmente ocorreu a ressignificação da experiência da doença ou se, quando os oficineiros consideraram a Aids como uma melhora, uma benção, não seria uma espécie de expiação: pequei, agora devo pagar. Esse fato poderia ocorrer pela busca de sentido implícito na religiosidade popular, que permite reconstruir a experiência da doença supondo um contraste entre um passado de ignorância, pecado e sofrimento e um presente de retidão moral (Rabelo e Alves, 200o).

Os enunciados para fazer frente à doença mudaram durante o percurso do grupo, assim, o repertório que se iniciou predominantemente biomédico, passou do âmbito do biológico para o religioso. No final do processo, entendemos que à medida que ia se instaurando uma relação de confiança no grupo, as pessoas foram nos dizendo o que realmente pensavam e faziam, e que não consideram suficiente a atenção disponibilizada pelos serviços de saúde. O consolo e o sentido para a doença foram encontrados por meio da experiência espiritual proporcionada pelas religiões populares.

A religião e a espiritualidade são recursos poderosos de resistência e enfrentamento à doença, amplamente utilizados pelas classes populares no Brasil e na América Latina. Embora possam atuar como mecanismos de negação e manutenção do status quo, a religião e a espiritualidade abrem espaço para a aceitação do doente, para a escuta não julgadora, para a possibilidade do perdão e, principalmente, permitem dar outro sentido para a experiência da doença.

Os estudos sobre a religiosidade popular como espaço de resistência das classes populares têm enfocado duas perspectivas: uma delas considera a religião como alienante e mantenedora da opressão, reforçando os tradicionais aspectos de submissão, abnegação e culpa. A segunda posição busca entender o significado e as possíveis transformações que a religiosidade permite operar. Nesse sentido, a religião contribui como instrumento de luta e enfrentamento aos mecanismos de dominação/exploração como os de gênero, raça e classe social. Ao considerar a religiosi- 
dade popular como espaço de resistência, não se pode deixar de apontar a racionalidade própria da cultura das classes populares, plural e multifacetada, na qual a lógica individualista convive com o holismo, da qual faz parte a visão sincrética e dual, que permite incorporar em um mesmo sistema explicativo elementos contraditórios de dominação e de libertação (Grossi e Werba, 2001; Valla, 2001).

A fé e a espiritualidade oferecem um sentido para a vida, garantindo um espaço onde buscar consolo e encontrar energia para enfrentar a incerteza e o medo, a discriminação e o preconceito, a solidão, a dor e a proximidade da morte. Entendemos como outros autores (Rabelo e Alves, 2000; Valla, 2001; Vasconcelos, 2006) que as práticas simbólico-religiosas constituem estratégias de sobrevivência de que as classes populares lançam mão em uma sociedade que lhes nega seus direitos legítimos. O caminho da espiritualidade e da religião parece despontar como uma das trajetórias principais para lidar com problemas de saúde, incluindo-se a Aids.

Nos grupos de contadores de histórias, foram ouvidas as histórias de vida dos participantes, mas também as histórias escolhidas pelos pesquisadores, percebidas como possibilidades terapêuticas. Os contos populares constituem repositórios de estratagemas, de insigths, de resolução de conflitos. As histórias não foram selecionadas a priori, porque, de certa maneira, elas emergem a partir do grupo. Na oficina tratada neste artigo, foram escolhidas histórias que favoreceram a reflexão sobre a dupla polaridade do portador de HIV/Aids: de um lado o homem ferido e, de outro, um sujeito identificado com os poderes de cura.

Deste modo, os participantes do grupo, pobres, excluídos, soropositivos, abandonados pelos familiares e amigos revelam-se àqueles que ouvem, traduzem e anunciam a voz de deus. Como o curador ferido, eles podem ser investidos do poder de cuidado a outras pessoas em situação de doença, desolação e vulnerabilidade. 0 jogo inventado pelo grupo e executado por Sara através da leitura dos salmos, deixou claro o quanto a realidade é o resultado de uma construção e que, através dos processos sociais, criamos a nós mesmos e ao mundo que nos cerca (Spink, 2004b). Esse jogo de linguagem aponta para a importância do olhar e da palavra do outro na comunicação de cada pessoa consigo mesma.

Entender a religiosidade popular como estratégia de enfrentamento a doenças, incluindo a Aids, pode aproximar equipes de saúde dos usuários. Além disso, os dispositivos grupais, como os contadores de histórias, constituem espaços de discussão sobre a vida e tudo o que dela decorre, inclusive a doença, a dor e a morte.

\section{Considerações Finais}

Avaliamos a experiência das oficinas de contadores de histórias entendendo que a intervenção que criamos coletivamente apontou caminhos de mudança, ressignificação e resistência.

O processo de construção da intervenção foi constantemente refeito durante o trajeto de pesquisa: os oficineiros questionaram a importância do dispositivo "contar histórias", expressando certa desconfiança em relação à proposta, já que muitas vezes os pesquisadores utilizam as ONGs para coletar dados de pesquisa e não dão o retorno prometido, comem o bolo e deixam a louça para a gente lavar, nos disse um dos voluntários.

Por outro lado, os participantes solicitaram que aumentássemos o número de encontros previstos e foram se fazendo mais participativos durante o trajeto da pesquisa. Trouxeram à baila um tema que não tínhamos cogitado na organização da oficina - a religiosidade e a espiritualidade popular. Inicialmente ficamos surpresos e até desconcertados com a emergência desse tema, mas entendemos que ele faz parte do acervo das resistências da população e não emitimos juízos de valor a respeito das escolhas dos participantes.

Ao término das oficinas, Jezebel, que aderiu à proposta do Álbum de Vida, seguiu construindo o seu Álbum e um dos oficineiros integrou-se à ONG no programa de redução de danos. No último encontro, avaliamos conjuntamente o processo e eles nos disseram que o mais importante foi que comemos com eles, uma metáfora, acreditamos, da dialogicidade que atravessou o grupo. 


\section{Referências}

ASPA - APOIO, SOLIDARIEDADE E PREVENÇÃO À

Aids. Os números do vale. Disponível em: $<\underline{\text { http:// }}$ aspa.org.br/A_situa_O_da_Epidemia_de_HIV.doc>.

Acesso em: 20 ago. 2005.

BAKHTIN, M. M. Marxismo e filosofia da linguagem. São Paulo: Hucitec, 1981.

BASTOS, F. I.; SZWARCWALD, C. Aids e pauperização: principais conceitos e evidências empíricas.

Cadernos de Saúde Pública, Rio de Janeiro, v. 16, n. 1, p. 65-76, 2000.

BENJAMIN, W. O narrador. In: ADORNO, B. H. Os pensadores. São Paulo: Abril Cultural, 198o. p. 57-74.

BRANDÃO, C. R. (Org.). Pesquisa participante. 7. ed. São Paulo: Brasiliense, 1988.

BRASIL. Ministério da Saúde. Fios da vida: tecendo o feminino em tempos de Aids. Brasília, DF, 2003. Disponível em: <http://bvsms.saude.gov.br/bvs/ publicacoes/fios_da_vida.pdf $>$. Acesso em: 22 ago. 2004 .

BRASIL. Ministério da Saúde. O perfil da Aids no Brasil e metas de governo para controle da epidemia. Disponível em: <http://www.aids.gov.br/data/ documents/storedDocuments/\%7BB8EF5DAF-23AE4891-AD 36-1903553A3174\%7D/\% 7 B661DD73F-5Ao3$4 \mathrm{~A}_{2} \mathrm{~F}-\mathrm{A} 4 \mathrm{~A} 9-\mathrm{F} 14 \mathrm{Co}_{4} \mathrm{BA} 2 \mathrm{E} 18 \% 7 \mathrm{D} /$ metas.pdf $>$. Acesso em: 30 jun. 2005 .

CAPRARA, A.; VERAS, M. S. C. Hermenêutica e narrativa: a experiência de crianças com epidermólise bolhosa congênita. Interface:

Comunicação, Saúde, Educação, Botucatu, v. 9, n. 6, p. 131-146, 2005.

CARVALHO, I. C. Biografia, identidade e narrativa: elementos para uma análise hermenêutica.

Horizontes Antropológicos, Porto Alegre, v. 9, n. 19, p. 283-302, 2003.

CONNELLY, F. M.; CLANDININ, D. J. Relatos de experiencia e investigación narrativa. In: LARROSA, J. et al. Déjame que te conte: ensayos sobre narrativa y educación. Barcelona: Alertes, 1995. p. 11-59.
GARAY, A.; IÑIGUEZ, L.; MARTINEZ, L. La perspectiva discursiva en psicologia social. Disponível em: <http://www.antalya.uab.es/liniguez/Materiales/ publicaciones.asp $>$. Acesso em: 28 maio 2005.

GIFFIN, K. Pobreza, desigualdade e eqüidade em saúde: considerações a partir de uma perspectiva de gênero transversal. Cadernos de Saúde Pública, Rio de Janeiro, v. 18, p. 103-122, 2002. Suplemento 1.

GOOLISHIAN, H. A.; ANDERSON, H. Narrativa e self: dilemas pós-modernos da psicoterapia. In:

SCHNITMAN, D. F. (Org.). Novos paradigmas, cultura e subjetividade. Porto Alegre: Artes Médicas, 1996. p. 191-203.

GROSSI, P.; WERBA, G. Violências e gênero: coisas que a gente não gostaria de saber. Porto Alegre. EDIPUCRS, 2001.

HENNINGTON, E.; MENEGHEL, S. N. Homicídios em São Leopoldo. São Leopoldo: UNISINOS, 2005.

IÑIGUEZ, L. Análisis del discurso: manual para las ciencias sociales. Barcelona: UOC, 2004.

JEOLÁS, L.; FERRARI, R. Oficinas de prevenção em um serviço de saúde para adolescentes: espaço de reflexão e de conhecimento compartilhado. Ciênciae Saúde Coletiva, Rio de Janeiro, v. 8, n. 2, p. 611-62o, 2003.

MENEGHEL, S.; FARINA, O.; RAMÃO, S. Histórias de resistência de mulheres negras. Estudos Feministas, Florianópolis, v. 13, n. 3, p. 567-583, 2005.

MORIN, A. Pesquisa-ação integral e sistêmica: uma antropopedagogia renovada. Rio de Janeiro: DP\&A, 2004.

POTTER, J.; WETHERELL, M. Discourse and social psychology. London: Sage, 1987.

RABELO, M.; ALVES, P. C. Evidencias de aflicción y tratamiento en ámbito religioso. In: MINAYO, M. C. (Org.). Salud y equidad: una mirada desde las ciencias sociales. Rio de Janeiro: Fiocruz, 200o. p. 189-210.

RASERA, E.; JAPUR, M. Grupo de apoio aberto para pessoas portadoras do HIV: a construção da homogeneidade. Estudos de Psicologia, Natal, n. 1, p. 55-62, 2003 . 
RAUTER, C. Oficinas para quê? In: AMARANTE, P. (Org.). Ensaios: subjetividade, saúde mental, sociedade. Rio de Janeiro: Fiocruz, 200o. p. 267-288.

SALOTTI, M. R.; FRANÇA, S. F. Contribuições da psicologia em instituições de cuidado aos indivíduos. Disponível em: <http://www.proex. reitoria.unesp.br/congressos/1_congresso/Saude e qualidade $>$. Acesso em: 20 ago. 2005.

SPINK, M. J. Linguagem e produção de sentidos. Porto Alegre: EDIPUCRS, 2004a.

SPINK, M. J. (Org.). Práticas discursivas e produção de sentidos no cotidiano: aproximações teóricas e metodológicas. 3. ed. São Paulo: Cortez, 2004b.

THIOLLENT, M. Crítica metodológica, investigação social e enquete operária. São Paulo: Polis, 1980.
VALLA, V. V. Globalização e saúde no Brasil: a busca da sobrevivência pelas classes populares via questão religiosa. In: VASCONCELOS, E. M. (Org.). A saúde nas palavras e nos gestos: reflexões da rede educação popular e saúde. São Paulo: Hucitec, 2001. p. 39-62.

VASCONCELOS, E. M. A espiritualidade no trabalho em saúde. Rio de Janeiro: Hucitec, 2006.

VERMELHO, L. L.; SIMÕES BARBOSA, R. H.; NOGUEIRA, A. S. Mulheres com Aids: desvendando histórias de risco. Cadernos de Saúde Pública, Rio de Janeiro, v. 15, n. 2, p. 369-379, 1999.

Recebido em: II/05/2007

Reapresentado em: 24/07/2007

Aprovado em: 14/08/2007 